aspartate aminotransferase, alanine aminotransferase, or $\gamma$-glutamyltransferase were transient and asymptomatic.

We conclude that dexamethasone clearly improves the antiemetic efficacy of ondansetron for the control of acute nausea and vomiting after high dose chemotherapy with cisplatin. It remains to identify the optimum antiemetic chedule to minimise delayed emesis as the next step in improving the acceptability of treatment to patients.

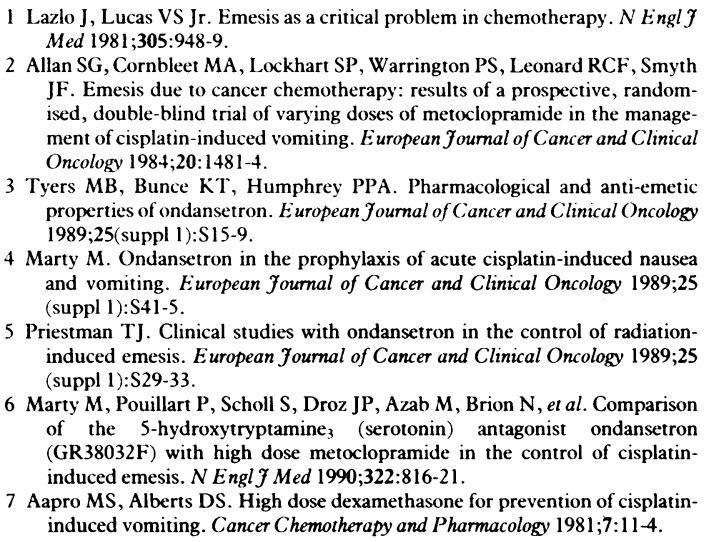
ised, double-blind trial of varying doses of metoclopramide in the management of cisplatin-induced vomiting. European fournal of Cancer and Clinical Oncology 1984;20:1481-4.

3 Tyers MB, Bunce KT, Humphrey PPA. Pharmacological and anti-emetic properties of ondansetron. European fournal of Cancer and Clinical Oncology 1989;25(suppl 1):S15-9.

4 Marty $M$. Ondansetron in the prophylaxis of acute cisplatin-induced nause and vomiting. European fournal of Cancer and Clinical Oncology 1989;25 (suppl 1):S41-5

5 Priestman TJ. Clinical studies with ondansetron in the control of radiationinduced emesis. European fournal of Cancer and Clinical Oncology 1989;25 (suppl 1):S29-33

6 Marty M, Pouillart P, Scholl S, Droz JP, Azab M, Brion N, et al. Comparison of the 5-hydroxytryptamine, (serotonin) antagonist ondansetron GR38032F) with high dose metoclopramide in the control of cisplatininduced emesis. N Engl f Med 1990;322:816-21.

7 Aapro MS, Alberts DS. High dose dexamethasone for prevention of cisplatininduced vomiting. Cancer Chemotherapy and Pharmacology 1981;7:11-4.

8 Allan SG, Cornbleet MA, Warrington PS, Golland IM, Leonard RCF, Smyth JF. Dexamethasone and high dose metoclopramide: efficacy in controllin cisplatin-induced nausea and vomiting. BMF 1984;289:878-9.

9 Hawthorn J, Cunningham D. Dexamethasone can potentiate the anti-emetic action of a $5 \mathrm{HT}_{3}$ receptor antagonist on cyclophosphamide-induced vomiting in the ferret. Br $\mathcal{F}$ Cancer 1990;61:56-60.

10 Cunningham D, Turner A, Hawthorn J, Rosin RD. Ondansetron with and without dexamethasone to treat chemotherapy-induced emesis. Lancel 1989; i: 1323 .

11 Smith DB, Newlands ES, Spruyt OW, Begent RHJ, Rustin GJS, Mellor B et al. Ondansetron (GR38032F) plus dexamethasone: effective anti-emetic prophylaxis for patients receiving cytotoxic chemotherapy. Br $\mathrm{f}$ Cancer prophylaxis for

12 Koch GG. The use of non-parametric methods in the statistical analysis of the two-period change-over design. Biometrics 1972;28:577-84

13. Prescott RJ. The comparison of success rates in crossover trials in the presence of an order effect. Applied Statistics 1981;30:9-15.

14 Hills M, Armitage P. The two-period crossover clinical trial. $\mathrm{Br}$ f Clin Pharmacol 1979;8:7-20.

15 Allan SG, Farquhar DF, Harrison DJ, Leonard RCF. Anti-emetic efficacy of dexamethasone in combination for outpatients receiving combination chemotherapy. Cancer Chemotherapy and Pharmacology 1986;18:86-7.

16 Benrubi GI, Norvell M, Nuss RC, Robinson H. The use of methylprednisolone and metoclopramide in control of emesis in patients receiving cisplatin. Gynecol Oncol 1985;21:306-13.

17 Roila F, Tonato M, Cognetti F, Cortesi E, Favalli G, Marangolo K, et al. A double-blind multi-centre randomised crossover study comparing the anti-emetic efficacy and tolerability of ondansetron vs ondansetron plus dexame dexamethasone in cisplatin-treated cancer patien.

18 Kris $M G$ G Controlling delayed vomiting: double-blind, randomised trial comparing placebo, dexamethasone alone, and metoclopramide plus dexamethasone in patients receiving cisplatin. $\mathcal{F}$ Clin Oncol 1989;7:108-14.

(Accepted 25 September 1991)

\title{
Bronchodilator treatment in moderate asthma or chronic bronchitis: continuous or on demand? A randomised controlled study
}

Constant P van Schayck, Edward Dompeling, Cees L A van Herwaarden, Hans Folgering, Andre L M Verbeek, Henk J M van der Hoogen, Chris van Weel

\section{Abstract}

Objective-To examine the effect of bronchodilator treatment given continuously versus on demand on the progression of asthma and chronic bronchitis and to compare the long term effects of a $\beta_{2}$ adrenergic drug (salbutamol) and an anticholinergic drug (ipratropium bromide)

Design-Two year randomised controlled prospective crossover study in which patients were assigned to one of two parallel treatment groups receiving continuous treatment or treatment on demand.

Setting-29 general practices in the catchment

Nijmegen University, PO Box 9101, Nijmegen 6500 HB, The Netherlands Constant $P$ van Schayck, PHD, research lecturer, department of general practice Edward Dompeling, MD, research fellow, department of general practice

Cees L A van Herwaarden, $\mathrm{MD}$, professor of pulmonology Hans Folgering, MD, head, pulmonary function laboratory Andre L M Verbeek, MD, senior lecturer, department of epidemiology

Henk J M van der Hoogen, statistician, department of general practice

Chris van Weel, MD, professor of general practice

Correspondence to: Dr C P van Schayck.

Patients -223 patients aged $\geqslant 30$ with moderate airway obstruction due to asthma or chronic bronchitis, selected by their general practitioners.

Interventions-1600 $\mu \mathrm{g}$ salbutamol or $160 \mu \mathrm{g}$ ipratropium bromide daily (113 patients) or salbutamol or ipratropium bromide only during exacerbations or periods of dyspnoea (110). No other pulmonary treatment was permitted.

Main outcome measures-Decline in ventilatory function and change in bronchial responsiveness, respiratory symptoms, number of exacerbations, and quality of life.

Results-Among 144 patients completing the study, after correction for possible confounding factors the decline in forced expiratory volume in one second was $-0.0721 /$ year in continuously treated patients and -0.0201 year in those treated on demand $(p<0.05)$, irrespective of the drug. The difference in the decline in patients with asthma was comparable with that in patients with chronic bronchitis (asthma: 0.092 $v-0.025 \mathrm{l}$ /year; chronic bronchitis: $-0.082 v-0.031$ 1/year). Bronchial responsiveness increased slightly $(0.4$ doubling dose) with continuous treatment in chronic bronchitis, but exacerbations, symptoms, and quality of life were unchanged. Salbutamol and ipratropium bromide had comparable effects on all variables investigated.

Conclusions-Continuous bronchodilator treatment without anti-inflammatory treatment accelerates decline in ventilatory function. Bronchodilators should be used only on demand, with additional corticosteroid treatment, if necessary.

\section{Introduction}

Asthma and chronic bronchitis are considered to be progressive diseases. ${ }^{12}$ The hypothesis has been put forward that early continuous bronchodilator treatment of reversible airflow obstruction will improve their prognosis, ${ }^{3}$ and this led to the recommendation to use continuous inhaled $\beta_{2}$ adrenergic drugs as a first step in treating chronic airflow obstruction. ${ }^{45}$ How ever, recent reports indicate adverse effects caused by continuous use of $\beta_{2}$ adrenergic inhalants, ${ }^{6-8}$ resulting in advice to reserve these drugs for treatment on demand ${ }^{89}$ Neither of these contradictory recommendations are based on evidence from intervention studies lasting long enough to establish an effect on decline in ventilatory function, which is generally believed to be the most important measure of progression of asthma or chronic bronchitis. Another question is which type of bronchodilator inhalant is more efficacious in long term treatment of asthma or chronic bronchitis: an anticholinergic drug or a $\beta_{2}$ adrenergic drug? Until now only the immediate bronchodilating effects of these drugs have been compared. Adverse effects of the continuous use of bronchodilators have 
been reported only with respect to $\beta_{2}$ adrenergic inhalants. It is important to assess whether this negative effect is specific for $\beta_{2}$ adrenergic drugs or common to all bronchodilators. Therefore the long term effects of other bronchodilators, such as anticholinergic drugs, should be studied as well.

In this study the long term effects of bronchodilator treatment (continuous versus on demand, and salbutamol versus ipratropium bromide) were investigated over two years in 223 patients with moderate airflow obstruction. Effects of treatment were assessed in terms of annual decline in ventilatory function, change in bronchial responsiveness, number of exacerbations, respiratory symptoms, quality of life, and patient's preference for treatment.

\section{Patients and methods} PATIENTS

Twenty nine general practitioners in the catchment area of this university selected all their patients aged 30 and over with symptoms of asthma or chronic bronchitis. ${ }^{10}$ We included in the study only subjects who showed a moderate airflow obstruction (forced expiratory volume in one second $\left(\mathrm{FEV}_{1}\right) \leqslant$ predicted value $^{11}$ minus $2 \mathrm{SD}$ but $\geqslant 50 \%$ of predicted) or an established bronchial hyperresponsiveness (provocative concentration of histamine causing $20 \%$ decline in $\mathrm{FEV}_{1}\left(\mathrm{PC}_{20}\right.$ histamine $\left.) \leqslant 8 \mathrm{~g} / \mathrm{l}\right)$, or both. Patients with other pulmonary or life threatening diseases (for example, carcinoma) or dependency on corticosteroids were excluded. Subjects were selected only if, in the opinion of the general practitioner and investigators, they could be treated with bronchodilator monotreatment. Random samples of patients who refused to participate or who had been excluded showed that no bias had been introduced in the selection procedure. ${ }^{10}$

The criteria for diagnosing asthma and chronic bronchitis were based on the standards for diagnosis formulated by the American Thoracic Society. ${ }^{12}$ Chronic bronchitis was defined as a continuous airflow obstruction $\left(\mathrm{FEV}_{1} \leqslant 85 \%\right.$ of the predicted value) combined with chronic cough or chronic production of sputum for at least three months a year, for at least two successive years. Asthma was defined as a reversible obstruction (increase in $\mathrm{FEV}_{1} \geqslant 15 \%$ of the initial value, 60 minutes after the inhalation of $400 \mu \mathrm{g}$ salbutamol and $80 \mu \mathrm{g}$ ipratropium bromide) in combination with bronchial hyperresponsiveness $\left(\mathrm{PC}_{20}\right.$ histamine $\leqslant 8 \mathrm{~g} / \mathrm{l})$ and the presence of dyspnoea and wheezing or allergy, or both. Although separate features of asthma and chronic bronchitis were not mutually exclusive, the combination of features was such that no patients with asthma also had a diagnosis of chronic bronchitis and vice versa. ${ }^{713}$ All patients were extensively informed about the trial, both in writing and orally, and gave oral consent. The randomised study was approved by the Nijmegen University's ethics committee.

\section{STUDY DESIGN}

After a screening visit ${ }^{10}$ patients entered an eight week washout period, during which corticosteroids and cromoglycate (if used) were stopped and only the trial treatment on demand was permitted. Patients were then randomly assigned to one of the two parallel treatment groups: continuous treatment (four dry powder inhalations of $400 \mu \mathrm{g}$ salbutamol or four of 40 $\mu \mathrm{g}$ ipratropium bromide daily) or treatment on demand (dry powder inhalations of salbutamol or ipratropium bromide only during exacerbations or periods of dyspnoea).

Patients were randomly allocated to use salbutamol during one year and ipratropium bromide during the other in a crossover design (Fig 1). The long term effects were expected to be less distinct with respect to the drug than to the treatment regimen, and the variation within patients was expected to be less than between patients. Therefore it was decided to use a crossover design for the drugs and not for the treatment regimen. All four treatment groups were equally represented in each general practice to exclude possible effects arising between doctors ("balanced allocation of treatment"). The study was of single blind design (blind observer) as most patients could easily distinguish between the (side) effects of the study drugs.

Patients who used the bronchodilator treatment on demand were instructed carefully that it should not be used to prevent symptoms but only to treat symptoms when present. The patients made an accurate weekly report of all treatment used. Patient compliance was maintained by regular telephone contact and home visits and checked by counting the unused drugs every three months.

The main purpose of this study was to investigate the effect of continuous treatment versus treatment on demand of bronchodilators alone. Any necessary additional treatment was an exclusion criterion and therefore an end point in the study because the effect of this necessary additional treatment (probably with inhaled corticosteroids) was expected to overshadow completely a possible difference between the two treatment regimens.

All exacerbations were treated in a standard way by the general practitioner: with a broad spectrum antibiotic and a 10 day course of oral prednisone. Otherwise, no other pulmonary treatment was permitted.

\section{MEASUREMENTS}

Spirometry and $P C_{20}$ histamine - Ventilatory function indices $\left(\mathrm{FEV}_{1}, \mathrm{FEV}_{1} /\right.$ vital capacity (VC) and increase in $\mathrm{FEV}_{1}$ after bronchodilation) were assessed seven times in periods free of exacerbations ${ }^{14}$ (measurements 0 to 6 in fig 1). The $P_{20}$ histamine was assessed five times during the same sessions (measurements $1,2,3$, 5,6 in fig 1). Bronchodilator treatment was stopped for at least eight hours before the start of the measurements of $\mathrm{PC}_{20}$ histamine and $\mathrm{FEV}_{1} . \mathrm{PC}_{20}$ histamine was assessed according to the method of Cockcroft et al. ${ }^{15}$ Reversibility of airflow obstruction was measured 60 minutes after inhalation of $400 \mu \mathrm{g}$ salbutamol and $80 \mu \mathrm{g}$ ipratropium bromide. Increase in $\mathrm{FEV}_{1}$ was expressed as a percentage of the value before bronchodilator treatment. The ventilatory function and $\mathrm{PC}_{20}$ tests were performed by two laboratory assistants using a Microspiro HI-298 spirometer (Chest Corporation, Japan)..$^{16}$

Symptoms, experienced health, and exacerbationsRespiratory symptoms were assessed by the Medical Research Council questionnaire at the beginning and end of the study and quantified on a scale of zero to eight. ${ }^{10}$ Additionally, the severity of cough, sputum production, and dyspnoea were each scored weekly by the patients on a scale of zero to four $(0=$ no complaints

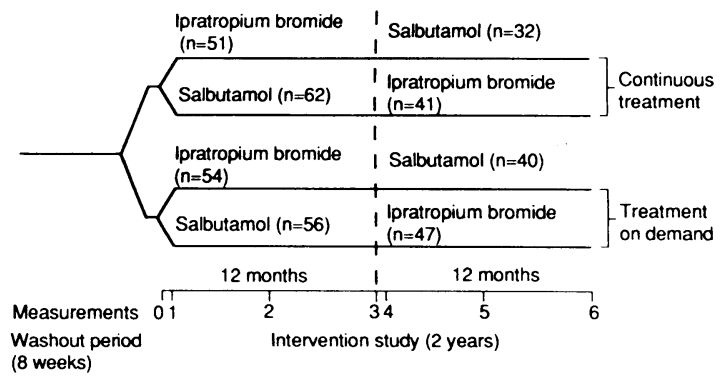

FIG 1-Study design. After an eight week washout period patients were randomly assigned to one of two parallel treatment groups (continuous treatment or treatment on demand) and to receive salbutamol and ipratropium bromide in a crossover design ( $n=$ numbers of patients at start and at end of study) 
$4=$ severe complaints). A total score for each week was obtained by adding the three separate scores. Experienced health ("quality of life") was assessed with the Nottingham health profile ${ }^{17}$ at the start of the study and after 12 and 24 months. The number and duration of exacerbations were assessed by the general practitioner. Exacerbations were defined according to Fletcher, modified according to Boman et al..$^{14}$

Smoking, allergy and treatment before study-History of smoking was retrospectively assessed in pack years, and during the study the number of cigarettes smoked each day was recorded weekly. Allergy was tested by means of seven radioallergosorbent tests (to pollen from weeds, grasses, and trees; cats and dogs; house dust mites; and Aspergillus fumigatus). Patients were considered to be allergic if at least one test result was positive. Information about pulmonary treatment used in the year preceding the study was provided by the general practitioner.

Statistical analysis - To determine the sample size of the study population we estimated that a clinically relevant difference in decline in $\mathrm{FEV}_{1}$ between the two parallel treatment groups would be $0.041 /$ year or more. With a $\beta$ value ( $1-\beta=$ power) of 0.20 and an $\alpha$ value (significance level) of $0 \cdot 05$, the total number of patients completing the study had to be 156 .

The principle of intention to treat was not used in the analysis as this study was more directed at fundamental questions concerning the therapeutic regimen than at its feasibility.$^{18}$ Patients in the crossover treatment group, the small group of 16 patients that continued their first year's treatment (see results), and the patients that dropped out of the study were analysed separately. Decline in $\mathrm{FEV}_{1}$ was calculated by averaging individual slopes calculated by linear regression. Decline in ventilatory function and change in bronchial responsiveness, respiratory symptoms,

TABLE I -Number of patients completing and dropping out of study and reasons for dropping out

\begin{tabular}{|c|c|c|c|c|c|c|c|c|c|c|}
\hline & \multirow[b]{2}{*}{ Start } & \multicolumn{9}{|c|}{ Study period (months) } \\
\hline & & 6 & & 12 & & 18 & & 24 & & Total \\
\hline No of patients & 223 & & & 188 & & 16 & & 160 & & \\
\hline No of patients dropping out in preceding six months & & & & 3 & & 2 & & 4 & & 63 \\
\hline Because of study treatment & & 19 & & 1 & & 20 & & & & 40 \\
\hline Advice of general practitioner & 4 & & & & 1 & & & & 5 & \\
\hline Need for corticosteroids & 10 & & 1 & & 19 & & & & 30 & \\
\hline Salbutamol not sufficient & 1 & & & & & & & & 1 & \\
\hline Ipratropium bromide not sufficient & 4 & & & & & & & & 4 & \\
\hline Because of other reasons & & 13 & & 2 & & 4 & & 4 & & 23 \\
\hline Deceased & & & & & 1 & & 1 & & 2 & \\
\hline Malignant disorders & 3 & & & & & & & & 3 & \\
\hline Emigration & & & 1 & & & & & & 1 & \\
\hline Lack of motivation & 10 & & 1 & & 3 & & 3 & & 17 & \\
\hline
\end{tabular}

TABLE II-Baseline clinical characteristics and treatment in year preceding study in patients who completed study and those who dropped out

\begin{tabular}{|c|c|c|c|c|}
\hline & \multicolumn{2}{|c|}{$\begin{array}{l}\text { Paticnts completing study } \\
\text { with: }\end{array}$} & \multicolumn{2}{|c|}{$\begin{array}{l}\text { Patients dropping out } \\
\text { because of: }\end{array}$} \\
\hline & $\begin{array}{l}\text { Crossover } \\
\text { treatment }\end{array}$ & $\begin{array}{l}\text { Continued } \\
\text { treatment }\end{array}$ & $\begin{array}{c}\text { Insufficient } \\
\text { treatment }\end{array}$ & $\begin{array}{l}\text { Other } \\
\text { reasons }\end{array}$ \\
\hline No & 144 & 16 & 40 & 23 \\
\hline$\%(\mathrm{No})$ men & $56(81)$ & $50(8)$ & $50(20)$ & $74(17)$ \\
\hline$\%$ (No) with asthma & $35(51)$ & $50(8)$ & $53(21)$ & $43(10)$ \\
\hline Mean (SD) age (years) & $52(12)$ & $46(12)$ & $57(12)^{\star}$ & $55(12)$ \\
\hline$\%(\mathrm{No})(\mathrm{ex})$ smokers & $81(117)$ & $88(14)$ & $78(31)$ & $87(20)$ \\
\hline No of pack years & 16 & 16 & 15 & 22 \\
\hline$\%(\mathrm{No})$ allergic & $24(35)$ & $38(6)$ & $38(15)$ & $26(6)$ \\
\hline Mean (SD) symptom score (questionnaire) & $4 \cdot 7(1 \cdot 8)$ & $5 \cdot 6(2 \cdot 0)$ & $4 \cdot 8(1 \cdot 7)$ & $5 \cdot 0(1 \cdot 6)$ \\
\hline $\operatorname{Mean}(\mathrm{SD}) \mathrm{FEV}_{1}(\mathrm{l})$ & $2 \cdot 41(0.79)$ & $2.37(0.74)$ & $2.02(0.58)^{\star \star}$ & $2.34(0.59)$ \\
\hline Mean (SD) FEV $\mathrm{FV}_{1} / \mathrm{VC}(\%)$ & $63(15)$ & $63(10)$ & $59(15)$ & $67(12)$ \\
\hline Mean (SD) reversibility of obstruction (\%) & $16(18)$ & $17(17)$ & $22(20)^{\star}$ & $14(10)$ \\
\hline Geometric mean $\mathrm{PC}_{20}(\mathrm{~g}$ histamine $/ \mathrm{l})$ & 8 & 5 & $4^{\star}$ & 8 \\
\hline \multicolumn{5}{|l|}{ Treatment in preceding year: } \\
\hline$\%$ (No) taking bronchodilator treatment on demand & $33(47)$ & $25(4)$ & $18(7)$ & $35(8)$ \\
\hline$\%$ (No) taking continuous bronchodilator treatment & $36(52)$ & $31(5)$ & $75(30)^{\star \star \star}$ & $30(7)$ \\
\hline$\%\left(\right.$ No) taking $\beta_{2}$ adrenergic drug & $56(81)$ & $38(6)$ & $70(28)$ & $52(12)$ \\
\hline$\%$ (No) taking anticholinergic drug & $12(17)$ & $19(3)$ & $13(5)$ & $9(2)$ \\
\hline$\%$ (No) taking corticosteroids & $14(20)$ & $13(2)$ & $60(24)^{\star \star \star}$ & $22(5)$ \\
\hline
\end{tabular}

${ }^{\star} \mathrm{p}<0.05,{ }^{\star \star} \mathrm{p}<0.005,{ }^{\star \star \star} \mathrm{p}<0.001$ differences between study group with crossover treatment and three other groups.
TABLE III - Baseline clinical characteristics of 223 patients treated continuously and on demand

\begin{tabular}{|c|c|c|}
\hline & $\begin{array}{l}\text { Continuously } \\
\text { treated } \\
\text { patients }\end{array}$ & $\begin{array}{l}\text { Patients } \\
\text { treated on } \\
\text { demand }\end{array}$ \\
\hline No & 113 & 110 \\
\hline$\%(\mathrm{No})$ men & $59(67)$ & $54(59)$ \\
\hline$\%$ (No) with asthma & $39(44)$ & $42(46)$ \\
\hline Mean (SD) age (years) & $53(12)$ & $52(12)$ \\
\hline$\%(\mathrm{No})(\mathrm{ex})$ smokers & $85(96)$ & $78(86)$ \\
\hline No of pack years & 19 & $14^{\star}$ \\
\hline$\%$ (No) allergic & $28(32)$ & $27(30)$ \\
\hline Mean (SD) symptom score (questionnaire) & $4 \cdot 9(1 \cdot 7)$ & $4.8(1.9)$ \\
\hline Mean (SD) FEV $_{1}$ (1) & $2.26(0.73)$ & $2.39(0.7$ \\
\hline Mean (SD) FEV 1 /VC (\%) & $62(14)$ & $63(14)$ \\
\hline Mean (SD) reversibility of obstruction (\%) & $18(21)$ & $16(15)$ \\
\hline Geometric mean $\mathrm{PC}_{20}(\mathrm{~g}$ histamine $/ \mathrm{l})$ & 8 & 8 \\
\hline
\end{tabular}

${ }^{\star} \mathrm{p}<0 \cdot 05$, difference between treatment groups.

number of exacerbations, and quality of life were analysed by analysis of covariance. All values werge adjusted for smoking behaviour before and during the study, sex, age, height, allergy, initial $\mathrm{FEV}_{1}$ (\% $\overline{\mathbf{\theta}}$ predicted value), and initial $\mathbf{P C}_{20}$ histamine. Subjects with asthma and chronic bronchitis were analyse separately. Before analysis, the $\mathrm{PC}_{20}$ histamine valueso were $\log$ transformed. The effects of salbutamol and ipratropium bromide were calculated within patients with the $t$ test for paired differences if no period effect - that is, the effect of year one versus year twoo irrespective of the sequence of drugs in these two years - could be detected. ${ }^{18}$

\section{Results}

Baseline characteristics of patients - A total of 223 patients entered the study, of whom 110 received treatment on demand and 113 continuous treatmenu (fig 1). One hundred and sixty patients completed the two year study. Table I describes the characteristics of 63 patients who dropped out of the study, 40 of whorm stopped because of inadequate response to treatmen? shown by increasing signs and symptoms of airflo obstruction. In this group, the number of patiens treated continuously was twice as high as that of those treated on demand (27 $v 13 ; \mathrm{p}=0.03, \chi^{2}$ test). The number of patients using ipratropium bromide salbutamol was not significantly different $(21 v 19$ : The patients who dropped out of the study were oldes and had a worse clinical condition than those comple ing the study (table II). Those who dropped out fï other reasons did not differ significantly from those completing the study. Sixteen of the 160 patients whe completed the two year study did not respone adequately to the study treatment in the second yeas, having continuous dyspnoea or too many side effects and they resumed their first year's treatment: 9 continued taking salbutamol and five ipratropium bromide. These 16 patients did not differ from the patients receiving crossover treatment (table II). Tabete III describes the clinical characteristics at the start of the study of the 223 patients treated continuously ang on demand. The two treatment groups differed signife cantly only with respect to smoking history $(p<0.05 \Phi$ Table IV shows the characteristics of the 144 patients who completed the study with crossover treatment These four treatment groups also differed from each other only in the number of pack years.

Treatment during study - Patients treated on demand used the same number of dry powder inhalations salbutamol as of ipratropium bromide: the mediap number was 0.3 inhalations/day (range $0 \cdot 14-4.0$ inhat tions/day).

Effects on decline in FEV $V_{1}$-Decline in $\mathrm{FEV}_{1}$ continuously treated patients was $-0.0861 /$ year and in patients treated on demand $-0.0291 /$ year. The difference was $0.0571 /$ year $(95 \%$ confidence interval 0.004 to 


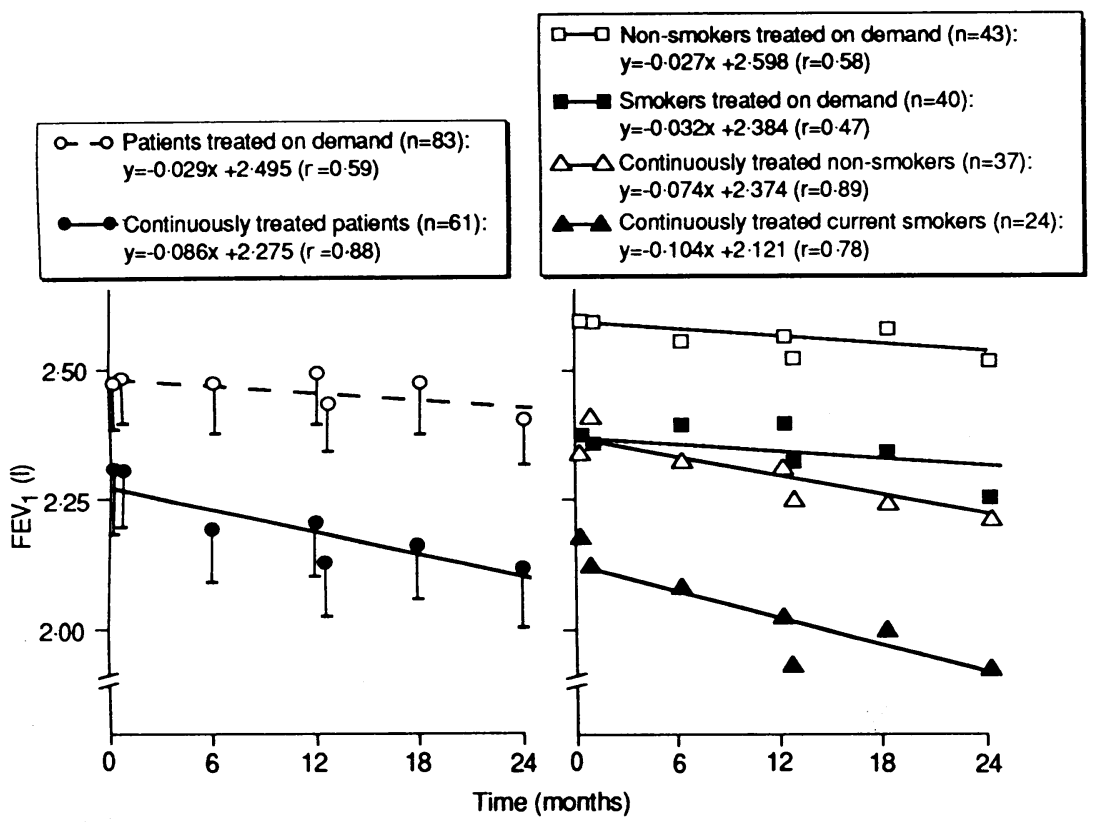

FIG 2-Decline in $F E V_{1}$ in group receiving crossover treatment. Mean $(S E)$ values for patients treated on demand and continuously and for smokers and non-smokers $\left(y=F E V_{1}(l), x=\right.$ number of years). Regression coefficients of patients treated on demand and continuously differed significantly $(p=0.02)$

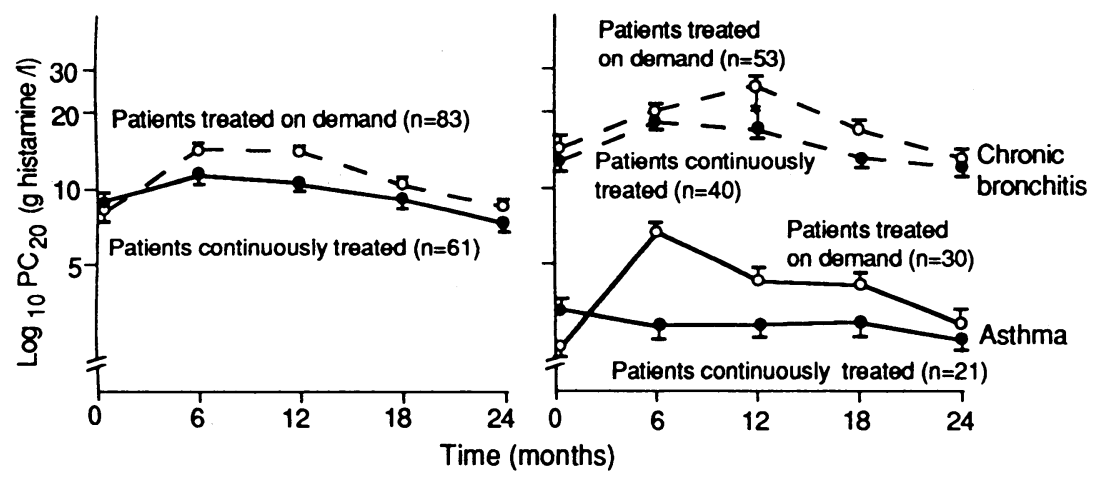

FIG 3-Bronchial responsiveness ( $P C_{20}$ histamine) of group receiving crossover treatment during study. Geometric mean $(S E)$ values for patients treated on demand and continuously and for asthma and chronic bronchitis ( ${ }^{\star}$ significant difference between treatments $(p<0 \cdot 05)$ )

$0 \cdot 1111$ year) $(\mathrm{p}<0.05)$ (fig 2). After correction for possible confounding factors (such as sex, age, height, smoking habits, and initial $\left.\mathrm{FEV}_{1}\right)$ the decline was $-0.0721 /$ year for continuously treated patients and $-0.0201 /$ year for those treated on demand. The difference was $0.052 \mathrm{l} /$ year $(0$ to $0 \cdot 106 \mathrm{l} /$ year $)(p=0 \cdot 05)$. The difference in decline between the two treatments in patients with chronic bronchitis $(-0.082$ (continuous) $v-0.031$ (on demand) $1 /$ year) was comparable with the decline in patients with asthma $(-0.092 v$ $-0.025 \mathrm{l}$ /year). Patients who smoked during the study showed a decline in lung function comparable with that in non-smokers, both those treated continuously and those treated on demand (fig 2). An additional analysis in which the patients who dropped out of the study were included as long as they participated confirmed these results: the regression slope for continuously treated patients was $0.097(\mathrm{SE} 0.026) \mathrm{l}$ /year and that of patients treated on demand 0.021 (SE 0.018) 1/year. Salbutamol and ipratropium bromide had no differen effects on the decline in $\mathrm{FEV}_{1}$ : the mean decline during the year salbutamol was used was 0.029 (SE 0.036) $1 /$ year less than during the year ipratropium bromide was administered, which was not significant $(p=0 \cdot 41)$. No reason could be found for the drop in $\mathrm{FEV}_{1}$ at the fourth measurement. This measurement took place within two weeks after the third measurement, and patients continued to use their treatment of the first year until the day of the fourth measurement. The decline in $\mathrm{FEV}_{1}$, however, was not strongly influenced by this systematic error. After omitting the fourth measurement the regression coefficients of all six subgroups did not change more than 0.0041 /year and the correlation coefficients increased by $0 \cdot 02-0 \cdot 10$.

Effects on bronchial responsiveness - The mean $\mathrm{PC}_{20}$ histamine was not significantly lower during continuous treatment than during treatment on demand $(0.5$ doubling dose on average, $p=0.29)$ (fig 3). In patients with chronic bronchitis the only significant difference was after 12 months $(0.4$ doubling dose, $\mathrm{p}<0.05)$. Salbutamol and ipratropium bromide had the same influence on the $\mathrm{PC}_{20}$, in both patients with asthma and those with chronic bronchitis.

Effects on symptoms, experienced health, and exacerbations - The treatment regimen did not significantly influence symptoms measured weekly by the patients (continuous $v$ on demand: $3 \cdot 2 v 2 \cdot 5, \mathrm{p}=0 \cdot 14$ ) or yearly by means of the MRC questionnaire (continuous $v$ on demand: $4.6 v 4 \cdot 0, \mathrm{p}=0.08)$. The type of drug influenced symptoms measured neither weekly nor yearly $(p=0.26, p=0.67$ respectively). Experienced health (energy, pain, emotions, sleep, social limitations, and mobility problems) was not influenced either by the treatment regimen or by the drug (all $p$ values $>0 \cdot 20)$. The mean number of exacerbations during continuous treatment was $0.85 /$ year and during treatment on demand $0 \cdot 73 /$ year $(p=0 \cdot 75)$. The duration of the exacerbation during continuous treatment was 1.8 weeks and during treatment on demand 1.4 weeks $(p=0.31)$. The type of drug had no influence on the number and duration of exacerbations $(p=0.42$, $\mathrm{p}=0 \cdot 15$ respectively).

Preference of patients-After having used both salbutamol and ipratropium bromide for one year each, more patients preferred salbutamol. This preference for salbutamol occurred only in patients who had used the drugs on demand $(38 / 83,46 \% v 18 / 83,22 \%$,

TABLE IV-Baseline clinical characteristics of patients who completed crossover treatment according to whether they had asthma or chronic bronchitis and to treatment groups

\begin{tabular}{|c|c|c|c|c|c|c|}
\hline & \multicolumn{2}{|c|}{ Patients with: } & \multicolumn{4}{|c|}{ Patients receiving: } \\
\hline & Asthma & $\begin{array}{c}\text { Chronic } \\
\text { bronchitis }\end{array}$ & $\begin{array}{l}\text { Ipratropium } \\
\text { bromide- } \\
\text { salbutamol on } \\
\text { demand }\end{array}$ & $\begin{array}{l}\text { Ipratropium } \\
\text { bromide- } \\
\text { salbutamol } \\
\text { continuous }\end{array}$ & $\begin{array}{l}\text { Salbutamol- } \\
\text { ipratropium } \\
\text { bromide on } \\
\text { demand }\end{array}$ & $\begin{array}{l}\text { Salbutamol- } \\
\text { ipratropium } \\
\text { bromide } \\
\text { continuous }\end{array}$ \\
\hline No & 51 & 93 & 38 & 29 & 45 & 32 \\
\hline$\%(\mathrm{No}) \mathrm{men}$ & $49(25)$ & $60(56)$ & $50(19)$ & $62(18)$ & $53(24)$ & $63(20)$ \\
\hline$\%$ (No) with asthma & 100 & 0 & $42(16)$ & $31(9)$ & $31(14)$ & $38(12)$ \\
\hline Mean (SD) age (years) & $50(12)$ & $53(12)$ & $50(12)$ & $53(14)$ & $52(13)$ & $54(10)$ \\
\hline$\%(\mathrm{No})$ (ex)smokers & $71(36)$ & $87(81)^{\star}$ & $79(30)$ & $86(25)$ & $76(34)$ & $88(28)$ \\
\hline Mean (SD) No of pack years & $13(16)$ & $18(16)$ & $14(17)$ & $18(18)$ & $13(16)$ & $21(15)^{\star}$ \\
\hline$\%(\mathrm{No})$ allergic & $36(18)$ & $18(17)^{\star}$ & $24(9)$ & $37(11)$ & $27(12)$ & $9(3)$ \\
\hline Mean (SD) symptom score (questionnaire) & $4 \cdot 8(1 \cdot 8)$ & $4 \cdot 7(1 \cdot 8)$ & $4 \cdot 7(1 \cdot 8)$ & $5 \cdot 0(1 \cdot 6)$ & $4.4(1.9)$ & $5 \cdot 0(1 \cdot 6)$ \\
\hline Mean (SD) FEV $_{1}(\mathrm{I})$ & $2 \cdot 27(0 \cdot 79)$ & $2.48(0.79)$ & $2.44(0.78)$ & $2 \cdot 27(0 \cdot 81)$ & $2 \cdot 52(0 \cdot 80)$ & $2.32(0.79)$ \\
\hline Mean (SD) FEV 1 VC $(\%)$ & $59(18)$ & $65(13)^{\star}$ & $64(13)$ & $58(15)$ & $64(16)$ & $64(15)$ \\
\hline Mean (SD) reversibility of obstruction (\%) & $24(23)$ & $11(12)^{\star \star}$ & $12(12)$ & $19(21)$ & $17(19)$ & $14(20)$ \\
\hline Geometric mean $\mathrm{PC}_{20}(\mathrm{~g}$ histamine $/ \mathrm{l})$ & $3(3)$ & $14(3)^{\star \star}$ & $8(4)$ & $7(3)$ & $8(4)$ & $9(4)$ \\
\hline
\end{tabular}

${ }^{\star} \mathrm{p}<0.05,{ }^{\star} \mathrm{p}<0.001$, differences between asthma and chronic bronchitis and between all four treatment groups. 
$\mathrm{p}<0.05$, one sample proportion test; $27 / 83$ patients had no preference); patients who had used the drugs continuously did not show this preference $(20 / 60,33 \%$ $v 21 / 60,35 \% ; 19 / 60$ had no preference).

\section{Discussion}

The results of this study do not confirm the hypothesis that continuous bronchodilator treatment reduces the decline in ventilatory function in patients with moderate airflow obstruction. Continuously treated patients had an annual decline in $\mathrm{FEV}_{1}$ that was three to four times higher than that in patients treated on demand. The annual decline in the group treated on demand was comparable with that in asthmatic and bronchitic subjects in a sample from the general population. ${ }^{19}$ The difference in decline was not caused by different conditions of the treatment groups at the start of the study, as the decline was corrected for possible confounding variables-for example, sex, past and current smoking behaviour, and initial $\mathrm{FEV}_{1}$. No influence of these variables was evident (all $p$ values $>0 \cdot 8$ ). Previous treatment was not a confounder either: coninuously treated patients had not received more corticosteroids or cromoglycate in the year preceding the study than patients treated on demand.

The short period of this study could discriminate decline in $\mathrm{FEV}_{1}$ between the two treatment regimens because of three reasons: firstly, a relatively large number of patients was studied; secondly, seven measurements of $\mathrm{FEV}_{1}$ were used; and, thirdly, the data for $\mathrm{FEV}_{1}$ fitted clearly in a linear model (explained variations of the measurements were more than $90 \%$ ).

Continuous bronchodilation seems to worsen rather than improve the prognosis, as far as the decline in $\mathrm{FEV}_{1}$ is concerned. This might be explained by bronchodilators failing to influence the inflammatory processes underlying the disease. A long term continuous bronchodilator treatment without antiinflammatory treatment could lead to adverse effects. $^{7820}$ In this study continuous bronchodilator treatment tended to increase bronchial responsiveness when compared with treatment on demand but only significantly so in patients with chronic bronchitis during part of the study. The need for antiinflammatory treatment was emphasised by the observation that the condition of most of the 40 patients who dropped out of the study because of insufficient bronchodilator treatment improved after the use of corticosteroids. Two thirds of these patients were treated continuously with bronchodilators during the study.

Although $\mathrm{FEV}_{1}$ clearly declined in continuously treated patients, the decline was not accompanied by a significant increase in exacerbations and symptoms or a perceived poorer quality of life. Patients with continuous bronchodilator treatment may tolerate precipitating situations better and may therefore be more exposed to sensitising agents. ${ }^{8}$ Continuous bronchodilation without anti-inflammatory treatment probably masks the decline in ventilatory function and suppresses the subjective need for additional anti-inflammatory treatment. ${ }^{21}$ Lack of awareness of this decline may mislead both doctor and patient and may be a reason why many patients in general practice who actually need anti-inflammatory treatment are still treated with only bronchodilators, not only in the Netherlands ${ }^{10}$ but also in the United Kingdom ${ }^{22}$ and probably in many other countries. A combination of bronchodilators and inhaled corticosteroids is advised when the need for bronchodilators is increasing. ${ }^{23}$

Recently, comparable findings were presented by Sears et al.$^{8}$ Regular inhalation of the $\beta_{2}$ adrenergic drug fenoterol for six months was associated with poorer overall control in 40 of their 64 asthmatic subjects. Control of asthma was judged by peak flow rates, symptom diaries, and use of additional treatment. Although that study was the longest study so far, it was too short to examine the effect on decline in ventilatory function. As continuous use of both salbutamol and ipratropium bromide and, from the study of Sears et al,$^{8}$ fenoterol seems to have adverse effects on the control of the disease it is likely that these effects are not specific to one certain drug but to bronchodilators generally. Moreover, as the results of our study were comparable for asthma and chronic bronchitis the possible deleterious effects of the continuous use of bronchodilators seems applicable to both conditions.

No differences between the long term effects of the $\beta_{2}$ adrenergic drug salbutamol and the anticholinergic drug ipratropium bromide were observed. Nevertheless, the number of patients in Dutch general practices treated with salbutamol is five times higher than that of those treated with ipratropium bromide, ${ }^{10}$ which may be explained by one result of our study-namely, that patients treated on demand prefer salbutamol to ipratropium bromide. This preference is probably due to the more rapid bronchodilating effect of salbutamol, which is apparent within five minutes compared with 15 to 30 minutes for ipratropium bromide.

Recently, long acting $\beta_{2}$ adrenergics have become available. Patients may be even more misled by the apparent wellbeing produced by these long acting bronchodilators, as they are more effective in suppressing symptoms - for example, morning dyspnoea. ${ }^{24}$ The results of this study suggest that treatment with these long acting drugs should not be a substitute for treatment with inhaled corticosteroids.

On the basis of these results the use of bronchodilator inhalants without additional treatment in patients with moderate airflow obstruction should be restricted to treatment on demand. If there seems to be an increasing need for bronchodilators additional treatment, such as corticosteroid treatment should be used.

We thank the Dutch Asthma Foundation and Boehringer Ingelheim Netherlands for their financial support; Mrs L Bierman and Mrs A Raaymakers for measuring ventilatory function and bronchial responsiveness; all the general practitioners and patients who took part in the study; Mr P G H Mulder for statistical advice and Mr R P Akkermans for help with computing; and Drs S T Weiss, D S Postma, I Gregg, and $P M$ van Grunsven for their advice on the manuscript.

1 Strachan DP, Anderson HR, Bland JM, Peckham C. Asthma as a link between chest illness in childhood and chronic cough and phlegm in young adults. chest illness in child $1988 ; 296: 890-3$.

2 Peto $\mathrm{R}$, Speizer FE, Cochrane AL, Moore F, Fletcher CM, Tinker CM, et ol. The relevance in adults of airflow obstruction, but not of mucus hypersecreion, to morality from chronic lung disease. Am Rev Respir Dis 1983;128: $491-500$.

3 Postma DS, de Vries K, Koëter GH, Sluiter HJ. Independent influence of reversibility of airflow obstruction and nonspecific hyperreactivity on the long-term course of lung function in chronic airflow obstruction. Am Rev Respir Dis 1986;134:276-80.

4 Rebuck AS, Chapmann KR. Asthma. 2. Trends in pharmacologic therap Can Med Assoc f 1987;136:483-8.

5 Sinclair BL, Clarke DWJ, Sears MR. Use of anti-asthma drugs in New Zealand. Thorax 1987;42:670-5

6 Sears MR, Rea HH, Fenwick J, Gillies AJD. 75 Deaths in asthmatics prescribed home nebulisers. BMf 1987;294:477-80.

7 Van Schayck CP, Graafsam SJ, Visch MB, Dompeling E, van Weel C, van Herwaarden CLA. Increased bronchial hyperresponsiveness after inhaling salbutamol during one year is not caused by subsensitization to (a)

8 Sears MR, Taylor DR, Print CG, Lake DC, Li Q, Flammery EM, et al Regular inhaled beta-agonist treatment in bronchial asthma. Lancet Regular inhaled beta-agonist treatment in bronchial asthma. Lancel
1990:336:1391-6. 1990;336:1391-6.

9 Mitchell EA. Is current treatment increasing asthma mortality and morbidity? Thorax 1989;44:81-4.

10 Van Schayck CP, van Weel C, Folgering H, Verbeek ALM, van Herwaarden CLA. Treatment of patients with chronic airflow obstruction by general practitioners and chest physicians. Scand f Prim Health Care 1989;7:137-42.

11 Quanier $\mathrm{Ph}$. Standardised lung function testing. Bulletin Europeen de Physiopathologie Respiratoire 1983;19(suppl 5):7-10.

12 American Thoracic Society. Standards for the diagnosis and care of patients with chronic obstructive pulmonary disease (COPD) and asthma. Am Rev Respir Dis 1987;136:225-43.

13 Van Schayck CP, Folgering H, Harbers H, Maas KL, van Weel C. Effects of allergy and age on responses to salbutamol and ipratropium bromide in allergy and age on responses to salbutamol and ipratropium bro 
14 Boman G, Bäcker U, Larsson S, Melander B, Wählander L. Oral acetylcysteine reduces exacerbation rate in chronic bronchitis: report of a tria organised by the Swedish society for pulmonary diseases. Eur 7 Respir Dis 1983;64:405-15.

15 Cockcroft DW, Killian DN, Mellon JJA, Hargreave FE. Bronchial reactivity to inhaled histamine; a method and clinical survey. Clin Allergy 1977;7 237-43.

16 Dompeling E, van Schayck CP, Folgering H, van den Hoogen HJM, van Weel C. Accuracy, precision and linearity of the portable flow-volume mete Microspiro HI-298. Eur Respir $\mathcal{J}$ 1991;4:612-5.

17 Hunt SM, McEwen J, McKenna SP. Measuring health status: a new tool for clinicians and epidemiologists. 7 R Coll Gen Pract. 1985;35:185-8.

18 Pocock SJ. Clinical trials. A practical approach. London: John Willey, 1983:114-9,176-86.
19 Burrows B, Bloom JW, Traver GA, Cline MG. The course and prognosis of different forms of chronic airways obstruction in a sample from the general population. N Engl f Med 1987;317:1309-14.

20 Sanjar S, Morley J. Airway hyperreactivity. Lancet 1988;ii:160-1.

21 Barnes PJ. Effect of corticosteroids on airway hyperresponsiveness. Am Rev Respir Dis 1990;141:S70-6.

22 Weir DC, Sherwood Burge P. Use of corticosteroids in patients with chronic airflow obstruction by physicians in the west Midlands. Thorax 1990;45:791.

23 British Thoracic Society. Guidelines for management of asthma in adults. I Chronic persistent asthma. BMf 1990;301:651-3.

24 Crompton GK. $\beta_{2}$-agonists in asthma. Lancet 1991;337:43-4.

\title{
Elective total hip replacement: incidence, emergency readmission rate, and postoperative mortality
}

\author{
Valerie Seagroatt, Heng Soon Tan, Michael Goldacre, Christopher Bulstrode, Ian Nugent, \\ Leicester Gill
}

\section{Abstract}

Objectives-To report the incidence of elective total hip replacement and postoperative mortality, emergency readmission rates, and the demographic factors associated with these rates in a large defined population.

Design-Analysis of linked, routine abstracts of hospital inpatient records and death certificates.

Setting-10 hospitals in six districts in Oxford Regional Health Authority covered by the Oxford record linkage study.

Subjects-Records for 11607 total hip replacements performed electively in 1976-85.

Main outcome measures-Incidence of operation, postoperative mortality, relative mortality ratios, and incidence of emergency readmission.

Results-NHS operation rates increased over time from 43 to 58 operations $/ 100000$ population Variation in operation rates between districts reduced over time. Operation rates were on average $25 \%$ higher in women than men. There were 93 deaths (11/1000 operations) within 90 days of the operation and 208 emergency readmissions $(28 / 1000$ operations) within 28 days of discharge. Postoperative mortality and emergency readmission rates increased with age. No significant trend with time was found. Mortality in the 90 days after the operation was 2.5 -fold higher $(1.9$ to 3.0$)$ than in the rest of the first postoperative year. This represented an estimated excess of $6.5(4.2$ to 8.8$)$ early postoperative deaths/1000 operations. Most deaths were ascribed to cardiovascular events. Thromboembolic disease was the commonest reason for emergency readmission.

Conclusions - The pronounced increase in operations in districts with initially low rates suggests a trend towards greater equity in the local provision of NHS hip arthroplasty. The early postoperative clusters of deaths attributed to cardiovascular disease and of readmissions for thromboembolic disease suggest that there is scope for investigating ways of reducing the incidence of major adverse postoperative events.

\section{Introduction}

Hip arthroplasty is one of the most common and successful major elective operations. People waiting for hip operations in England constitute an importan component of waiting lists, and the Department of Health has established targets for operation rates in health authorities. ${ }^{1}$ Descriptive studies of the epidemiology of hip arthroplasty have been published but, particularly the studies of outcome, have generally come from individual specialist centres or been based on fairly small numbers of operations. ${ }^{2-13}$ A modest amount of routine information about rates of hip arthroplasty in England has been published in the Hospital In-patient Enquiry. ${ }^{14}$ In addition, a review ${ }^{\circ}$ article on assessing the need for total hip replacements $ᄋ$ has recently been published. ${ }^{15}$ But there is no routine statistical information available about readmissions or deaths after the operation. We used the Oxford record ${ }_{\varnothing}^{\infty}$ linkage study to report operation rates, postoperative mortality, and readmission rates in a large, defined population. As these data show that postoperative mortality varies considerably depending on whether $\vec{\emptyset}$ the arthroplasty is elective or the result of an emergency. admission, this report is confined to elective hip arthroplasty; our findings on post-traumatic operations will be reported elsewhere.

\section{Methods}

RECORDS

The Oxford record linkage study is a collection of computerised abstracts of hospital records and death certificates collected such that data on successive events relating to the same patient can be linked together. Death records were available for all patients in the study area regardless of place of death. We 3 analysed data on hospital admissions in 1976-85, when data collection was undertaken in six districts of the Oxford region, covering a resident population of 1.9 million. The record linkage study collects data on all patients admitted to hospital for NHS care. Hospitals on that treat private patients have been invited to submit $D$ data, but their submission of data on private care has been inconsistent. Unless otherwise indicated the results in this study refer to NHS operations only.

All records that included the Office of Population Censuses and Surveys operation code for total hip replacement (810) were identified. ${ }^{16}$ Unfortunately

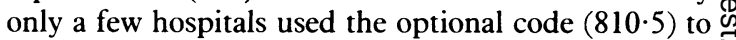
distinguish between primary and revision replacements. Patients with femoral fracture were excluded. A validation study of coding was undertaken in one hospital, which performed about half the hip replace- $\mathbb{D}$ ments in the region, by cross checking between the record linkage study files and the hospital's operating theatre registers.

All hip replacements undertaken in the six districts were included in the calculations of incidence of the흘 operation. In the analysis of postoperative mortality ? patients who had had a second operation in the 90 days after a first arthroplasty were excluded, so all the 